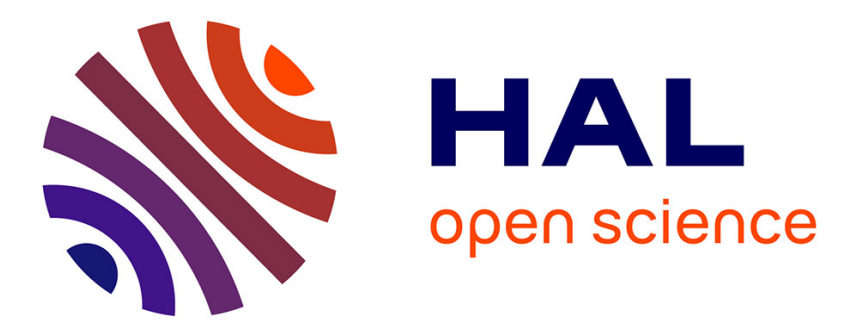

\title{
Trophic position and individual feeding habits as drivers of differential PCB bioaccumulation in fish populations
}

\author{
T. Masset, V. Frossard, M.E. Perga, N. Nathalie Cottin, C. Piot, S. Cachera,
} E. Naffrechoux

\section{- To cite this version:}

T. Masset, V. Frossard, M.E. Perga, N. Nathalie Cottin, C. Piot, et al.. Trophic position and individual feeding habits as drivers of differential PCB bioaccumulation in fish populations. Science of the Total Environment, 2019, 674, pp.472-481. 10.1016/j.scitotenv.2019.04.196 . hal-02165156

\section{HAL Id: hal-02165156 \\ https://hal.univ-smb.fr/hal-02165156}

Submitted on 22 Oct 2021

HAL is a multi-disciplinary open access archive for the deposit and dissemination of scientific research documents, whether they are published or not. The documents may come from teaching and research institutions in France or abroad, or from public or private research centers.
L'archive ouverte pluridisciplinaire HAL, est destinée au dépôt et à la diffusion de documents scientifiques de niveau recherche, publiés ou non, émanant des établissements d'enseignement et de recherche français ou étrangers, des laboratoires publics ou privés.

\section{(ㄷ)(1) $\$$}

Distributed under a Creative Commons Attribution - NonCommerciall 4.0 International 
2 Trophic position and individual feeding habits as drivers of differential PCB bioaccumulation in fish populations.

Masset T. ${ }^{a *}$, Frossard V. ${ }^{b}$, Perga M.E. ${ }^{c}$, Cottin N. ${ }^{a}$, Piot C. ${ }^{a}$, Cachera S. ${ }^{d}$ and Naffrechoux E. ${ }^{a}$

a Univ. Savoie Mont-Blanc, LCME, 73000 Chambéry, France

b Univ. Savoie Mont-Blanc, INRA, CARRTEL, 73000 Chambéry, France

c UNIL, IDYST, CH-1015 Lausanne, Suisse

${ }^{d}$ CISALB, 73000 Chambéry, France

\section{Abstract}

Despite PCBs being banned since the 1980's, some European peri-alpine lakes, and consequently their fish populations, are still contaminated by these xenobiotics. We investigated the relative contribution of physiological and trophic factors that could be implicated in fish PCB bioaccumulation in Lake Bourget (France), one of the most contaminated in Europe, by collecting Arctic char $(n=55)$ and European whitefish $(n=89)$ from 2013 to 2016. Concentrations of 7 indicator PCBs were $9-168$ ng.g w.w $w^{-1}$ in whitefish and $90-701$ ng.g w. $w^{-1}$ in Arctic char. The fish trophic positions calculated from $\delta^{15} \mathrm{~N}$ values were positively correlated with PCB concentrations $\left(r^{2}=0.45 ; p<0.001\right)$. A biomagnification model relying on TP and lipid content of fish was then designed, and it confirmed this result. A Bayesian mixing model based on $\delta{ }^{13} \mathrm{C}$ and $\delta{ }^{15} \mathrm{~N}$ values was used to estimate the relative contribution of preys in the fish diet, which explained a significant proportion of the biomagnification model residuals (i.e., $17 \%$ ). Zooplankton consumption was negatively correlated with $\mathrm{PCB}$ concentrations, whereas consumption of chironomids enhanced the PCB burden in fish. Correction of the biomagnification model for individual diets of fish increased the correlation between the predicted and measured fish $P C B$ contents $\left(R^{2}=0.71\right.$; $\mathrm{p}<0.001$ ), highlighting the importance of fish feeding habits in the bioaccumulation process.

Keywords: biomagnification, Polychlorobiphenyls, peri-alpine lake, Arctic char, whitefish, Bayesian mixing model

\section{Introduction}

As in numerous places around the world, some lakes in Europe are still contaminated by polychlorinated biphenyls (PCBs), either from primary sources or from global atmospheric pollution ${ }^{1-3}$. Lake Geneva in Switzerland ${ }^{4}$, and Lake Como ${ }^{5}$ and Lake Maggiore in Italy ${ }^{6}$ were found to be highly contaminated with PCBs. Of all the subalpine lakes, Lake Bourget is probably the most heavily polluted ${ }^{7}$.

Fish PCB exposure has numerous consequences: reduction of their metabolic capacities ${ }^{8,9}$, induction of genotoxic effects ${ }^{10}$ and introduction of intersex occurrence ${ }^{11}$. Bioaccumulation of pollutants in fish can occur through two distinct mechanisms. First, bioconcentration describes the accumulation process of water-dissolved compounds via tegumentary and branchial absorption. Second, when the thermodynamic activity of a compound in an organism exceeds its diet, bioaccumulation of the pollutant can be attributed to biomagnification. In contrast to bioconcentration, biomagnification varies with the contamination level of the diet. It depends on the species feeding preferences, increasing with each 
food-web trophic level ${ }^{12,13}$. Therefore, through biomagnification, predation on contaminated fish can also enhance the PCB burden of the upper trophic food chain ${ }^{14-17}$. Biomagnification of lipophilic compounds such as PCBs has been related to three different factors: (i), the nature of the contaminant itself, commonly quantified by the octanol-water coefficient ( $\mathrm{K}_{\text {ow }}$ ); (ii) the physiology of the exposed individual, i.e., its lipid content (as fatter fish tend to accumulate more contaminant), body size and age (as the contaminant gets diluted with individual growth), and sex (as spawning could decrease concentration in females) ${ }^{18,19}$; and (iii) trophic factors such as living habitat (i.e., feeding location) and diet preferences ${ }^{20,21}$, food chain length and therefore trophic position (TP $)^{22}$.

The relative contribution of mechanisms by which contaminants bioaccumulate in fish has been extensively studied but remains quite uncertain in alpine lakes, where environmental conditions (carbon sources, temperature, contaminant concentrations) can greatly differ yearly and seasonally. Some studies could not link PCB levels in fish to any biomagnification processes, as PCB contamination was neither correlated with body size, living habitat nor TP, especially in mountain lakes. Indeed, Catalan et $\mathrm{a}^{23}$ questioned the relative importance of biomagnification in contamination of salmonids in highaltitude Lake Redo and suggested that bioconcentration could be a significant mechanism for PCB bioaccumulation. Perga et al ${ }^{24}$ concluded that $\mathrm{PCB}$ contamination may be mainly due to a nontrophic (i.e., bioconcentration) process in Lake Muzelle. In contrast, numerous studies have shown that a contaminated diet was responsible for bioaccumulation in fish in the American Great Lakes ${ }^{15,25,26}$ and that contamination levels increased with $\mathrm{TP}^{14,22}$. As a lipophilic contaminant, differences in fat content result in differences in $\mathrm{PCB}$ contamination within the same species ${ }^{14}$. Living habitat and particularly carbon sources (benthic or planktonic) were environmental factors directly linked to discrepancies in PCB contamination between individuals and between species ${ }^{20}$ when PCB contamination is heterogeneous between trophic habitats. Even though their work did not focus on PCBs, Kahilainen et al. ${ }^{21}$ went further and recently showed that ecomorphological divergences in whitefish could be responsible for a large part of the intraspecies variability in mercury bioaccumulation.

PCB contamination in our study lake (Lake Bourget), remains considerable today; water concentrations exceed US-EPA guidelines for the protection of aquatic wildlife ${ }^{27}$ and highly contaminated sediment. Therefore, Arctic char (Salvelinus alpinus) fishing is prohibited by a prefectural decree, despite being the most emblematic fish species of Alpine lakes ${ }^{28}$. European whitefish (Coregonus lavaretus), the other typical fish of Alpine lakes, represents 90\% (91 tons/year) of the fish caught in Lake Bourget since 2014 (S. Cachera, personal communication 2017). These species feed from pelagic and littoral food-web and are suspected to venture into the benthic zone ${ }^{29}$, which make them vulnerable to PCB biomagnification, possibly to different extents. For these reasons, Arctic char and whitefish were identified as the most relevant species to investigate for the research hypothesis of the present study. Herein, we assumed that biomagnification necessarily implies that fish PCB contamination can be related to fish physiological and trophic parameters, i.e., under the biomagnification hypothesis, interspecies, interindividual and interannual PCB contamination levels shall be determined by (i) physiological parameters (body size or lipid content), (ii) living habitat (determined from carbon isotope composition $\delta^{13} \mathrm{C}$ ), or (iii) fish TP (estimated from nitrogen stable isotope composition $\delta^{15} \mathrm{~N}$ ). We investigated the potential importance of the fish feeding habits ${ }^{30,31}$ (different foraging behavior leading to a differential use of carbon sources) on the interindividual variability of the PCB burden. Finally, we strove to highlight how a combination of those parameters could result in important PCB contamination discrepancies in fish from a single lake. 


\subsection{Study site:}

Lake Bourget is located on the northwest edge of the French Alps. It is the largest natural lake in France, with a surface of $44 \mathrm{~km}^{2}$, a length of $18 \mathrm{~km}$ and a width of between 1.6 and $3.5 \mathrm{~km}$, for a mean depth of $85 \mathrm{~m}$ (maximum: $145 \mathrm{~m}$ ). Lake Bourget is a meso-oligotrophic lake with a mean temperature of $14.7^{\circ} \mathrm{C}$ and 4.5 to $10.1 \mathrm{mgO}^{2} \mathrm{~L}^{-1}$ of dissolved oxygen at 140 and 2 meters depth, respectively. Its $\mathrm{pH}$ is 8.3 and the conductivity is $299 \mu \mathrm{s} . \mathrm{cm}^{-1}$ for the period 2015-2017 32,33 . PCB inputs are mainly due to a point source located upstream on the Tillet River, which was contaminated from 1930 to 1987 by an electrical transformer factory using Pyralène ${ }^{\mathrm{TM}}$. Despite the cessation of the industrial activity and the recent cleanup of the downstream section of the river from 2012 to 2014, Lake Bourget is still contaminated. Even though contamination decreased in the last decades, superficial sediments remain polluted with a mean indicator PCB concentration (sum of PCB $28,52,101,118,153,138,180$ ) of $12.1 \pm 6.4 \mathrm{ng} . \mathrm{g}^{-1} \mathrm{~d} . \mathrm{w}$, with yet heterogeneous contamination of the lake, reaching $113 \mathrm{ng} \cdot \mathrm{g}^{-1} \mathrm{~d} . \mathrm{w}$ at the Tillet River outlet (Fig. S1). Consequently, the lake water still exceeds the USEPA recommended maximum concentration of 170 pg. $\mathrm{L}^{-1}$ for the protection of aquatic wildlife ${ }^{27}$, with a mean dissolved $57 \mathrm{PCBi}$ concentration of $322 \pm 102$ pg. $\mathrm{L}^{-1}$.

\subsection{Processing:}

\subsubsection{Sampling and preparation of organisms}

103 European whitefish $(n=89)$ and Arctic char $(n=55)$ were collected from 2013 to 2016 using net fishing (fish physiological characteristics can be found in Tab S1). The two species are suspected to be mobile in the water body, and exact locations were not reported. Diverse stomach content analyses (i.e., volumetric and qualitative estimations) punctually performed on fishes obtained from recreational and professional fishers revealed that the two fish species shared common prey in the lake, such as aquatic insects and zooplankton, with some piscivory also detected for Arctic char (data not shown). Consequently, similar resources were considered as possibly supporting whitefish and Arctic char in Lake Bourget: littoral (i.e., $-2 \mathrm{~m}$ to $-5 \mathrm{~m}$ in depth) and deep (i.e., $-20 \mathrm{~m}$ and $-40 \mathrm{~m}$ in depth) chironomids larvae, zooplankton (i.e., composite samples of Daphnia sp. and Bythotrophes sp.) plus young-of-the-year (yoy) perch for Arctic char. Yoy perch $(5-7.5 \mathrm{~cm})$ were caught in the pelagic compartment at approximately 15 $\mathrm{m}$ in depth. Chironomids $(\mathrm{n}=48)$ were collected at two depths $(2-5 \mathrm{~m}$ and 20-40 m) in September 2015 using an Ekmann grab and sieved using a $500-\mu m$ net. Zooplankton $(n=14)$ were sampled alongside with a $50-\mu \mathrm{m}$ net at the depth range of $0-20 \mathrm{~m}$.

All samples were transferred to the laboratory in a cooling box and immediately processed or stored at $18^{\circ} \mathrm{C}$ until further analysis. Organism processing has already been described previously ${ }^{34}$. Briefly, fish were dissected and filets ground using Ultraturax (3000 rpm). The same process was applied to chironomids with the whole organism. Five $\mathrm{g}$ of filet (1 $\mathrm{g}$ of chironomids) were spiked with an internal standard (PCB 116-d5), and an appropriate amount of anhydrous sodium sulfate $\left(\mathrm{Na}_{2} \mathrm{SO}_{4}\right)$ was added for water removal. PCB extraction was performed in heptane/acetone mixture $(75: 25 \mathrm{v} / \mathrm{v})$ for $1 \mathrm{~h}$ at $45^{\circ} \mathrm{C}$ in an ultrasonic bath. The solvent mixture was removed and the extraction procedure repeated once. Extracts were then purified on an SPE cartridge loaded with silica (previously acidified with $\mathrm{H}_{2} \mathrm{SO}_{4}$ to ensure lipid elimination of the extract) using a heptane/dichloromethane mixture, concentrated with TurboVap II and resuspended in $500 \mu \mathrm{L}$ of heptane. The lipid content in the fish filets were determined for every sample. After the PCB extraction procedure above-mentioned and before the purification step, $5 \mathrm{~mL}$ of the extract was transferred in a pre-weighted vial and evaporated under a gentle stream of nitrogen until steady weight. The mass collected in the vial corresponded to lipids and was ultimately used for calculation of lipid content in the fish filets. 
131 Heptane, acetone, dichloromethane and methanol were HPLC quality and purchased from Carlo Erba.

132 Anhydrous sodium sulfate was purchased from Fisher Chemical (analytical reagent grade). Silica gel 60

133 (70-230 mesh) for column chromatography was from Merck. Copper was activated with $10 \mathrm{~mL}$ of sulfuric

134 acid $1 \mathrm{~N}$ (Chimie-Plus) and then rinsed three times with Milli-Q water to neutral $\mathrm{pH}$ and, subsequently,

135 with acetone for water removal. Standard mixture of indicator PCB congeners $(28,52,101,118,138$,

$136153,180)$ at $100 \mu \mathrm{g} \cdot \mathrm{mL}^{-1}$ in iso-octane and internal standard PCB $116-\mathrm{d} 5$ at $100 \mu \mathrm{g} \cdot \mathrm{mL}^{-1}$ in iso-octane

137 were purchased from Cluzeau Info Lab (France).

\section{$138 \quad$ 2.2.3 PCB analysis}

139 All PCB solutions were analyzed using a Gas-Chromatography Clarus 580 from Perkin-Elmer with a 140 nonpolar fused silica capillary column Optima ${ }^{\circledR}$ HP-5-MS accent $30 \mathrm{~m} \times 0.25 \mathrm{~mm}$ from Machery-Nagel ${ }^{\circledR}$, 141 coupled with a Pulsed Discharge Detector in photoionization mode (Vici $\left.{ }^{\circledR}\right)$. The samples were injected in $142 \mathrm{split} / \mathrm{splitless}$ mode at $300^{\circ} \mathrm{C}$. Helium was used as the carrier gas $\left(1.0 \mathrm{~mL}\right.$. $\left.\mathrm{min}^{-1}\right)$. After injection, the oven 143 temperature was set at $60^{\circ} \mathrm{C}$ for $1 \mathrm{~min}$, and it was increased gradationally at $10^{\circ} \mathrm{C} / \mathrm{min}$ to $240^{\circ} \mathrm{C}$ and at $1445^{\circ} \mathrm{C} / \mathrm{min}$ to $320^{\circ} \mathrm{C}$ and kept steady for $5 \mathrm{~min}$. Quantification was ensured for the 7 indicator $\mathrm{PCB}$ congeners ( $P C B$ 28, 52, 101, 118, 153, 138, 180), because they represent a vast majority of the compounds found in Pyralene ${ }^{\circledR}$ mixtures commercialized in France ${ }^{35}$. Calibration curves were established with authentic standards, and PCB 116-d5 was used as the internal standard (Fig. S2). Extraction yields for each PCBi are presented in Tab. S2 but were not used for result correction; normalization to PCB116d5 values spiked before extraction accounted for extraction correction. Detection limits were determined as the mean response + three times the standard deviation of procedural blanks for each PCBi (Tab. S3). These concentrations were subtracted from the samples concentrations to avoid false positives.

\subsubsection{Stable isotope analysis}

After sampling and dissection, fish filets, chironomids and zooplankton were dried at $50^{\circ} \mathrm{C}$, ground into fine powder using a mortar and pestle and kept in tin capsules away from humidity prior to isotopic analysis. Samples in tin capsules were sent to SINLAB (NB, Canada). One mg was analyzed on a Finnigan Delta Plus mass spectrometer coupled with a Conflo II NC2500 Elemental Analyzer for $\delta^{13} \mathrm{C}$ and $\delta^{15} \mathrm{~N}$ quantification. Samples were calibrated against 7 plant and animal laboratory standards covering a wide range of $\delta^{13} \mathrm{C}$ and $\delta^{15} \mathrm{~N}$ values (i.e., from $-35.08 \%$ o to $-13.25 \%$ ond $0.02 \%$ o to $16.14 \%$, respectively). Three replicates for each sample were run. The precision values of the $\mathrm{C}$ and $\mathrm{N}$ isotope analyses were $<0.2 \%$.

\subsubsection{Statistical analysis}

163 All statistical tests were performed using the OriginPro 8 SRO software and R 3.5.0 software. All data were tested for normality using the Shapiro test and, if appropriate, for homoscedasticity using the Bartlett test. When appropriate, data were log-transformed to ensure normality and homoscedasticity. Differences in fish PCB concentrations and fish size, lipid content, $\delta^{15} \mathrm{~N}$ and $\delta^{13} \mathrm{C}$ between year and season were tested using an ANOVA or the Kruskal-Wallis test. Post hoc comparisons were performed using Tukey's honest significant difference (HSD) or Dunnett tests. The relationship between fish PCBi concentrations and the measured parameters (size, lipid content, $\delta^{15} \mathrm{~N}$ and $\delta^{13} \mathrm{C}$ ) were tested using Pearson correlations for normal variables or Spearman correlations otherwise.

\subsection{Modeling:}




\subsubsection{Resource contributions}

Bayesian mixing models (BMM) based on a Markov chain Monte Carlo simulation were used to assess prey contributions to the diet of the two species at an individual level. BMM offer the opportunity to account for the uncertainty (i.e., standard deviations) of the different data involved in the computation (i.e., isotope composition of prey, trophic fractionation, elemental concentration) and provide robust and accurate estimates of prey contributions to fish diets. The different resources considered as possibly supporting whitefish and Arctic char in Lake Bourget were littoral $(n=16)$ and deep $(n=26)$ chironomids, zooplankton $(n=14)$, plus yoy perch $(n=15)$ for Arctic char. $\delta^{15} \mathrm{~N}$ and $\delta^{13} \mathrm{C}$ isotopic values were used for computations. The trophic fractionations retained for carbon and nitrogen were those widely reported in the literature ${ }^{36,37}: \Delta \delta^{13} \mathrm{C}=0.8 \pm 1 \mathrm{sd}$ and $\Delta \delta^{15} \mathrm{~N}=3.4 \pm 1 \mathrm{sd}$. The computation of the Bayesian mixing models were performed using the $\mathrm{R}$ package $\operatorname{simmr}^{38}$ and considered $1.10^{4}$ iterations, four Markov chains and a burn-in period of $10^{3}$. Seasonal variability may bias prey contributions to fish diets, especially for short-lived prey. To account for this possible bias, BMM were also performed (data not shown) by increasing the standard deviation of zooplankton by 2 and 4 (i.e., to mimic possible seasonal variability of their isotopic values) which led to minor (i.e., a few percent) and nonsignificant (i.e., Kruskal-Wallis tests, $p>0.4$ ) changes in zooplankton contributions to the fish diets. Consequently, the prey contributions estimated from the BMM were poorly affected by changes in the spread of their isotopic values that would be expected if prey sampling would account for different seasons.

Salmonid muscle can exhibit high lipid contents that are typically ${ }^{13} \mathrm{C}$-depleted and may alter the $\delta^{13} \mathrm{C}$ values of their dorsal muscle ${ }^{39}$. Consequently, $\delta^{13} \mathrm{C}$ values for both whitefish and Arctic char were corrected according to Post et al. ${ }^{39}$, considering the sample $\mathrm{C} / \mathrm{N}$ ratio to estimate lipid content in the sample used for isotopic analysis following equation 1 :

$\delta^{13} C_{\text {corrected }}=\delta^{13} C_{\text {measured }}-3.32+0.99 \times C N_{\text {ratio }}$

\subsubsection{Trophic position}

The estimations of the trophic position at an individual level were performed based on the $\delta^{15} \mathrm{~N}$ values of the different preys weighted by their respective contributions to individual fish diets estimated by the BMM, as suggested by Post ${ }^{40}$. This approach enabled estimates of the trophic position of each whitefish ( $\left(\mathrm{P}_{\mathrm{WFind}}\right)$ and Arctic char $\left(\mathrm{TP}_{\mathrm{Acind}}\right)$ individual according to equations 2 and 3 , which generalized the initial formula of Vander Zanden ${ }^{37}$ for multiple baselines:

$$
\begin{aligned}
& T P_{\text {WFind }}=\left[\delta^{15} N_{\text {WFind }}-\left(\alpha_{\text {zoo }} \times \delta^{15} N_{\text {zoo }}+\alpha_{\text {invdeep }} \times \delta^{15} N_{\text {invdeep }}+\alpha_{\text {invlitto }} \times \delta^{15} N_{\text {invlitto }}\right)\right] / \\
& 3.4+\overline{T P}_{\text {resources }} \\
& T P_{\text {ACind }}=\left[\delta^{15} N_{\text {ACind }}-\left(\alpha_{\text {zoo }} \times \delta^{15} N_{\text {zoo }}+\alpha_{\text {invdeep }} \times \delta^{15} N_{\text {invdeep }}+\alpha_{\text {invlitto }} \times \delta^{15} N_{\text {invlitto }}+\right.\right. \\
& \left.\left.\alpha_{\text {perch }} \times \delta^{15} N_{\text {perch }}\right)\right] / 3.4+\overline{T P}_{\text {resources }}
\end{aligned}
$$

with $\delta^{15} \mathrm{~N}_{\text {WFind }}$ or $\delta^{15} \mathrm{~N}_{\text {ACind }}$ as the $\delta^{15} \mathrm{~N}$ values of individual fish, and $\alpha \times \delta^{15} \mathrm{~N}$ as the product of the proportions of the different resources to their $\delta^{15} \mathrm{~N}$ values. The mean trophic position of resources (i.e., $\overline{T P}_{\text {resources }}$ ) of whitefish was 2 , because zooplankton and invertebrate are typical primary consumers. $\overline{T P}_{\text {resources }}$ of Arctic char was 2.125 , because yoy perch is considered to have a trophic position of 2.5 .

At a population level, the mean trophic positions for the two fish species were compared to those estimated from a Bayesian framework recently developed by Quezada-Romegialli et al. ${ }^{41}$ to ensure the robustness of the results and support their trophic differences. This Bayesian approach considers the $\delta^{13} \mathrm{C}$ and $\delta^{15} \mathrm{~N}$ values of both whitefish and Arctic char, as well as those of their putative prey. The trophic 
fractionations of $\delta^{13} \mathrm{C}$ and $\delta^{15} \mathrm{~N}$ consisted of a vector of 188 simulated trophic fractionations (i.e., equal length of the total number of isotope data for the two fish species) following a normal distribution with the same mean and standard deviation as the BMM. Bayesian trophic positions were computed using the $\mathrm{R}$ package tRophicposition ${ }^{41}$ considering $2.10^{4}$ iterations and four Markov chains. In the model current implementation, consideration of more than two different baselines was not possible, while the two species feed at least on three or four different main resources. To be consistent in the computation of the trophic position for the two species, the two different baselines considered were zooplankton (i.e., pelagic resource) and deep invertebrates (i.e., benthic resource), since these resources had the highest contributions according to the BMM and accounted for the main differences in the $\delta^{15} \mathrm{~N}$ values of the resources.

\subsubsection{Biomagnification model}

Total PCB concentrations in fish muscle used in our model were estimated as twice the measured $57 \mathrm{PCBi}$ in our samples ${ }^{42}$. As we expect that fish physiology, feeding habits and bioaccumulation mechanisms should not differ among years and remain similar overtime, one single biomagnification model was built for the period 2013-2016. The biomagnification model was built considering TP, measured lipid contents and their putative interactions from every individual fish of both species together as follows:

$\log _{10} P C B_{\text {estimated }}=\alpha \times T P+\beta \times$ lipid content $+\gamma \times(T P \times$ lipid content $)$

with $\alpha, \beta$ and $\gamma$ as the regression coefficients estimated by the model and TP estimated from equations 2 and 3.

To examine individual data more precisely, the residuals were extracted (i.e., equation 5) and could help highlight the different processes of contamination. Specifically, negative residuals would indicate lower contamination than expected, whereas positive residuals would indicate higher contamination than expected.

Residuals $=\log _{10} P C B_{\text {obs }}-\log _{10} P C B_{\text {estimated }}$

To identify the origin of these different processes (i.e., under and over contamination), residuals were modeled as a function of the different common resource contributions shared by the two species previously estimated using the BMM (i.e., equation 6), which could highlight the influence of prey type on the variability of fish contamination levels.

Residuals $=\mathrm{f}\left(a \times \alpha_{\text {zoo }}+b \times \alpha_{\text {invdeep }}+c \times \alpha_{\text {invlitto }}+\varepsilon\right)(6)$

The difference in the proportions of preys in the diet of the different individuals could reflect specific feeding habits (i.e., FH). Consequently, equation 6 could also be formulated as follows:

Residuals $=\mathrm{f}(\mathrm{FH}+\varepsilon)$

Following these different steps, equation 8 provided a general formulation of the PCB concentration in the different fish muscles at an individual level accounting for the generic biomagnification (i.e., $\log _{10} P C B_{\text {estimated }}$ ) refined by a correction considering the individual feeding habits of the fish (i.e., $F H$ ):

$\log _{10} P C B_{\text {obs }}=\log _{10} P C B_{\text {estimated }}+\mathrm{FH}+\varepsilon$ 


\section{Results and discussion}

\subsection{Temporal, interspecies and interindividual variability in PCB contamination:}

Arctic char was significantly more contaminated than whitefish (Fig. 1), both when wet weight and lipidnormalized concentrations were considered (t-test, $p<0.0001$ for both tests). In light of the relationship between lipid content and PCBi contamination $\left(r^{2}=0.52 ; p<0.001\right)$ and of the important discrepancies regarding lipid contents between both species (i.e., mean lipid composition of 3.2\% for whitefish and 8.9\% for Arctic char, Tab. S1), only lipid-normalized PCBi concentrations in fish were considered thereafter. Interspecies and interindividual PCBi profiles were consistent between years, with a major contribution (i.e., 80\%) of heavy PCBi (Fig. S3).

Differences were observed between years for both species (ANOVA, $F_{3,51} p<0.05$ for Arctic char and $F_{2,76}$ p<0.05 for whitefish (Fig. 1)). Combining our data with data from 2008 from the French PCB follow-up program $^{43}$ emphasized the important decline of lake fish contamination due to the clean-up of the Tillet River between September 2012 and December 2013. Subsequently, a steady level of contamination was observed for both species.

Within both species, the interindividual variability of the PCBi concentrations was large (standard deviation of normalized PCBi concentration was $54 \%$ and $52 \%$ for whitefish and Arctic char, respectively). Those results encouraged us to determine the relative importance of trophic and physiological parameters potentially implicated in such interindividual variability.

\subsection{Physiological parameters and relationship with PCBi contamination:}

For both species, no strong relationship could be drawn between the physiological fish parameters (size and age) and the PCB contamination (data not shown). Fish physiology appeared to be different between both species. The relatively narrow range of sizes $(255 \mathrm{~mm}-480 \mathrm{~mm})$ and ages (1 year -5 years) for the target fish species sampled might be a reason behind the lack of a relationship with PCBs. A lack of increasing PCB contamination with size was observed by Olsonn et al. in small perch $(<20 \mathrm{~cm})$ in a Latvian lake ${ }^{44}$. An absence of contaminant-size relationship was also found for rainbow trout in Lake Michigan ${ }^{45}$. Metabolism of PCBs and elimination rates did not differ between Arctic char and whitefish since PCB profiles and particularly metabolizable PCB (PCB 28 and PCB 52) percentages were very similar for both species (Fig S3).

\subsection{Trophic plasticity of Arctic char and whitefish:}

302 Overall the two fish species had relatively similar $\delta^{13} \mathrm{C}$ values, ranging from $-34 \%$ to $-31 \%$. Mean annual $\delta^{13} \mathrm{C}$ values showed significant variabilities between years (one-way ANOVA, $F_{3,51}=5 ; p<0.01$ and $F_{2,76}=32 ; p<0.001$ for Arctic char and whitefish, respectively). Arctic char had a higher $\delta^{15} \mathrm{~N}$ than whitefish (mean value of $15.7 \%$ and $13.7 \%$, respectively, Wilcox test $p<0.0001$ ) confirming a piscivory behavior resulting in a higher trophic status. The isotopic measurements for the different resources considered to be consumed by whitefish and Arctic char did not overlap, although zooplankton and yoy perch exhibited lower variability than the benthic invertebrates (Fig. 2). The main differences in the 
isotopic compositions of these resources lay in their different $\delta^{15} \mathrm{~N}$ values, with pelagic resources (i.e., zooplankton and yoy perch) enriched by approximately $6 \%$ o compared to benthic resources.

311 The BMMs applied at an individual level highlighted similar general patterns for the two fish species,

\subsection{Trophic parameters and relationship with $\mathrm{PCBi}$ contamination:} concentrations in whitefish for all samples considered (Fig. 4). A finer analysis for each year was performed and showed the same negative results (Fig. S5 and S6). The same analyses were performed for Arctic char, and both trophic parameters $\delta^{13} \mathrm{C}$ and TP were unrelated to PCBi concentrations $\left(r^{2}=0 ; p\right.$ $>0.05$ and $r^{2}=0.22 ; p>0.05$, respectively) (Fig. 4). For whitefish, advanced testing of different years did not show any correlation (Fig. S5 and S6).

As in our study, a lack of intraspecies relationships between PCB concentrations and TP was also observed in Salmonids from the Great Lakes ${ }^{13,46}$. The authors hypothesized that this could be related to the trophic structure and dynamic of the food web. Vander Zanden et al. ${ }^{13}$ found that in a short-length food chain, no relationship between PCB concentrations and TP were observed in Lake Trout. However, our data showed that TP and PCB concentration data were correlated $\left(r^{2}=0.45 ; p<0.001\right)$ when both species were examined together, with an increase of the PCBi contamination with trophic position. This followed the findings of Vander Zanden et al. ${ }^{13}$, for which an increasing range of TP values could also enable the observation of a positive relationship between TP and PCB concentrations. The increase of PCB concentrations with TP could be an indicator of the biomagnification process. The Trophic Magnification Factor (TMF) is a reliable metric to assess biomagnification (i.e., TMF $>1$ ) in aquatic food webs $^{47}$. TMF can be determined as the regression slope of the following equation: $\log [P C B]=a T P+b$. In our study, a TMF value of 1.8 confirmed biomagnification.

At least two parameters (lipid content and TP) seem to account for a significant part of the PCB variability in fish. To clear up the different processes involved and the relative importance of biomagnification in fish contamination, we built a model to which our data were compared. 
This model was based on the correlation described by Vander Zanden et al. ${ }^{13}$, taking into account TP and lipid content. It enabled to estimate PCB concentrations in fish (a comparison between our model and the model of Vander Zanden et al. ${ }^{13}$ can be found in Fig. S7). PCB concentrations of fish individuals were estimated and compared with the measured PCB values (calculated as twice the measured $57 \mathrm{PCBi}$ concentration, see above). The biomagnification model using TP and the lipid content exhibited high performance $\left(r^{2}{ }_{\text {adj }}=0.64\right.$, Fig. $\left.6 \mathrm{~A}\right)$. Ordering the residuals of the biomagnification model enabled us to highlight possible differences in contamination mechanisms (Fig. 5). A large proportion of Arctic char (i.e., 64\%) tended to have positive residuals, indicating that they were more contaminated than predicted by the model. In contrast, $58 \%$ of whitefish exhibited the opposite patterns (i.e., less contaminated than predicted).

363 The origin of the individual differences between measured contamination and modeled contamination 364 (i.e., model residuals) was investigated regarding the different resources shared by the two species, which reflected their feeding habits. The fitted linear model shown in equation 7 indicated that the three shared resources could explain a significant proportion of the residuals of the biomagnification model $\left(r^{2}{ }_{a d j}=0.17, p<0.001\right)$. The model estimates provided important insights in the way the different resources could influence fish contamination. Both zooplankton and deep invertebrates were characterized by negative estimates suggesting that an increasing contribution of these resources would lead to lower contamination (PCB concentration in zooplankton was not measured in this work). In contrast, littoral invertebrates were associated with positive estimates, indicating that this resource may support positive residuals; that is, there were higher PCB concentrations than expected (27PCBi concentration of chironomids decreased from $541 \pm 378 \mathrm{ng} . \mathrm{g} \mathrm{w} \cdot \mathrm{w}^{-1}$ at the outlet of the Tillet River in 2015 down to $41 \pm 30$ ng.g w.w ${ }^{-1}$ at $-20 \mathrm{~m}$ to $-40 \mathrm{~m}$ ).

Predicted contamination of the biomagnification model associated with corrections for feeding habits indicated that most Arctic char (i.e., 78\%) had positive corrections, while most whitefish (i.e., 78\%) had negative corrections (Fig. 5). This result suggested that the feeding habits of fish may partly explain the discrepancies between observed and predicted PCB concentrations. Specifically, feeding habits of fish would tend to increase the predicted concentrations of the biomagnification model for Arctic char and decrease those predicted for whitefish.

The biomagnification model provided valuable information regarding the general variables responsible for PCB variability in fish muscles. Nonetheless, the complementary corrections for individual feeding habits allowed even more accurate predictions $\left(r^{2}\right.$ adj $\left.=0.71\right)$, which may be especially important considering the $\log _{10}$-scale (Fig. 6B). This was exemplified by the three highest concentrations in Arctic char (i.e., boxes in Fig. 6), for which the residuals were the most penalizing on a $\log _{10}$-scale. For these individuals, the biomagnification model alone showed a mean difference between predicted and measured PCB concentrations of $637 \pm 55 \mathrm{ng} \cdot \mathrm{g}^{-1}$, while once the feeding habits correction is applied, the difference decreases down to $253 \pm 83 \mathrm{ng} \cdot \mathrm{g}^{-1}$.

Altogether, the lipid content and trophic position accounted for a large part of the variability in the PCB contamination in fish from Lake Bourget. Our modeling, including correction for feeding habits, allowed us to account for significant complementary PCB variations not accounted for by the lipid content or trophic position and highlight that some fishes (mainly Arctic char) were highly contaminated due to feeding on benthic littoral invertebrate, whereas less contaminated fish (mainly whitefish) fed predominantly on zooplankton.

Intraspecies specialization in aquatic animals has been an emerging topic of interest the past few years ${ }^{30}$. Numerous studies have shown that ecological specialization could occur in fish ${ }^{31,48}$. Arctic char ecology is extremely difficult to encompass, because the intrapopulation variability of diverse aspects (morphology, feeding strategies, life-history strategies) can be complex ${ }^{49,50,48}$. Similarly, whitefish was also proved to 
exhibit various morphs in the lacustrine systems ${ }^{52-54}$. Recently, Kahilainen et al. ${ }^{21}$ showed that ecomorphological divergence could be responsible for differential mercury bioaccumulation in whitefish. Moreover, fish respiratory capacity can vary between species and also between individuals ${ }^{55,56}$, leading to possible difference in PCB metabolism rates. Therefore, intra and interspecies variation in PCB bioaccumulation could be partially explained by intra and interspecies physiological differences at the gills level. Hence, the diversity of behaviors and morphology potentially encountered for the same population could be partly responsible for the large span of PCB contamination observed, as different individuals could develop in high or low contamination environments in Lake Bourget.

Altogether, our results suggested that trophic parameters have a significant effect on PCB contamination variability between Arctic char and whitefish. Within species, feeding habits were shown to be responsible for a substantial part of the PCB burden. This study emphasized the importance of the feeding habits in the bioaccumulation process for Arctic char and whitefish in Lake Bourget.

Modeling or empirical studies based on the prediction of fish PCB burden according to the environmental compartment PCB concentration (water, sediment) are useful tools for managers. However, it should be kept in mind that considerable inter- and intraspecies variability exists that can be partly related to feeding habits. Consequently, estimates can greatly differ from actual measured values, especially in the most contaminated organisms, which are particularly concerning per safety guidelines. Therefore, as recently stressed by Mackay et al. ${ }^{57}$, caution should be taken when using models for regulatory purposes and field monitoring accounting for inter- and intraspecies variability, and spatial variability seems to remain a reliable way to assess the ecological state of lacustrine ecosystems. Field monitoring should include sampling of at least 7 fish per target species, as suggested by Amiard et Al. ${ }^{58}$, and it should be performed seasonally at several locations and depths within the lake in order to account for feeding habits and to prevent biases resulting from seasonal and spatial fish contamination.

\section{Acknowledgements}

The authors would like to thank ZABR CNRS and Agence de l'eau RMC, funders of the research program RESTOLAC (2013-2016) as well as OLA (Observatory on LAkes), (C OLA-IS, AnaEE-France, INRA Thononles-Bains, CISALB for IS OLA Data.

\section{Author information}

Corresponding author:

*Tel: +33 479758 898; email: Thibault.masset@univ-smb.fr

\section{Supplementary material}

Sediment sampling locations and associated congeners profile; example of chromatogram in ECD-PDID mode; whitefish and arctic char physiological characteristics; extraction yields and detection limits for the different matrices; mean PCB concentration and mean fish 7 indicator PCB congeners repartition; trophic positions determined with frequency; plots with yearly relationships between $\delta^{13} \mathrm{C}$ and TP with PCB concentration; bayesian approaches and relationship between biomagnification model developted in this study and Vander Zanden and Rasmussen (1996) model.

\section{References}


(1) Nellier, Y.-M.; Perga, M.-E.; Cottin, N.; Fanget, P.; Malet, E.; Naffrechoux, E. Mass Budget in Two High Altitude Lakes Reveals Their Role as Atmospheric PCB Sinks. Sci. Total Environ. 2015, 511, 203-213.

(2) Carrera, G.; Fernández, P.; Grimalt, J. O.; Ventura, M.; Camarero, L.; Catalan, J.; Nickus, U.; Thies, H.; Psenner, R. Atmospheric Deposition of Organochlorine Compounds to Remote High Mountain Lakes of Europe. Environ. Sci. Technol. 2002, 36 (12), 2581-2588.

(3) Castro-Jiménez, J.; Mariani, G.; Eisenreich, S. J.; Christoph, E. H.; Hanke, G.; Canuti, E.; Skejo, H.; Umlauf, G. Atmospheric Input of POPs into Lake Maggiore (Northern Italy): PCDD/F and Dioxinlike PCB Profiles and Fluxes in the Atmosphere and Aquatic System. Halogenated Persistent Org. Pollut. Dioxin 2005Selected Pap. 25th Int. Symp. Halogenated Environ. Org. Pollut. POPs Held Tor. Can. August 2005 2008, 73 (1, Supplement), S122-S130.

(4) Mathieu, A.; Babut, M. Contamination Des Poissons d'eau Douce Par Des Contaminants Persistants: Polychlorobiphényles (PCB), Dioxines, Furanes, Mercure. Etude Des Relations BioteSédiment Pour Les PCB. 2012.

(5) Bettinetti, R.; Quadroni, S.; Boggio, E.; Galassi, S. Recent DDT and PCB Contamination in the Sediment and Biota of the Como Bay (Lake Como, Italy). Sci. Total Environ. 2016, 542, 404-410.

(6) Binelli, A.; Ricciardi, F.; Provini, A. Present Status of POP Contamination in Lake Maggiore (Italy). Chemosphere 2004, 57 (1), 27-34.

(7) Naffrechoux, E.; Cottin, N.; Pignol, C.; Arnaud, F.; Jenny, J.-P.; Perga, M.-E. Historical Profiles of PCB in Dated Sediment Cores Suggest Recent Lake Contamination through the "Halo Effect." Environ. Sci. Technol. 2015, 49 (3), 1303-1310. https://doi.org/10.1021/es5043996.

(8) Jørgensen, E. H.; Vijayan, M. M.; Killie, J.-E. A.; Aluru, N.; Aas-Hansen, $\varnothing$.; Maule, A. Toxicokinetics and Effects of PCBs in Arctic Fish: A Review of Studies on Arctic Charr. J. Toxicol. Environ. Health A 2006, 69 (1-2), 37-52.

(9) Gauthier, P. T.; Evenset, A.; Christensen, G. N.; Jørgensen, E. H.; Vijayan, M. M. Lifelong Exposure to PCBs in the Remote Norwegian Arctic Disrupts the Plasma Stress Metabolome in Arctic Charr. Environ. Sci. Technol. 2017.

(10) Marabini, L.; Calò, R.; Fucile, S. Genotoxic Effects of Polychlorinated Biphenyls (PCB 153, 138, 101, 118) in a Fish Cell Line (RTG-2). Toxicol. In Vitro 2011, 25 (5), 1045-1052.

(11) Hinck, J. E.; Blazer, V. S.; Schmitt, C. J.; Papoulias, D. M.; Tillitt, D. E. Widespread Occurrence of Intersex in Black Basses (Micropterus Spp.) from US Rivers, 1995-2004. Aquat. Toxicol. 2009, 95 (1), 60-70.

(12) Gobas, F. A. Bioconcentration and Biomagnification in the Aquatic Environment. Handb. Prop. Estim. Methods Chem. Environ. Health Sci. 2000.

(13) Vander Zanden, M. J.; Rasmussen, J. B. A Trophic Position Model of Pelagic Food Webs: Impact on Contaminant Bioaccumulation in Lake Trout. Ecol. Monogr. 1996, 66 (4), 451-477.

(14) Rasmussen, J.; Rowan, D.; Lean, D.; Carey, J. Food Chain Structure in Ontario Lakes Determines PCB Levels in Lake Trout (Salvelinus Namaycush) and Other Pelagic Fish. Can. J. Fish. Aquat. Sci. 1990, 47 (10), 2030-2038.

(15) Kidd, K.; Hesslein, R.; Ross, B.; Koczanski, K.; Stephens, G.; Muir, D. C. Bioaccumulation of Organochlorines through a Remote Freshwater Food Web in the Canadian Arctic. Environ. Pollut. 1998, 102 (1), 91-103.

(16) Sørmo, E. G.; Salmer, M. P.; Jenssen, B. M.; Hop, H.; Bæk, K.; Kovacs, K. M.; Lydersen, C.; FalkPetersen, S.; Gabrielsen, G. W.; Lie, E. Biomagnification of Polybrominated Diphenyl Ether and Hexabromocyclododecane Flame Retardants in the Polar Bear Food Chain in Svalbard, Norway. Environ. Toxicol. Chem. 2006, 25 (9), 2502-2511. 
(17) Alava, J. J.; Ross, P. S.; Lachmuth, C.; Ford, J. K.; Hickie, B. E.; Gobas, F. A. Habitat-Based PCB Environmental Quality Criteria for the Protection of Endangered Killer Whales (Orcinus Orca). Environ. Sci. Technol. 2012, 46 (22), 12655-12663.

(18) Johnston, T. A.; Fisk, A. T.; Whittle, D. M.; Muir, D. C. Variation in Organochlorine Bioaccumulation by a Predatory Fish; Gender, Geography, and Data Analysis Methods. Environ. Sci. Technol. 2002, 36 (20), 4238-4244.

(19) Borgå, K.; Fisk, A. T.; Hoekstra, P. F.; Muir, D. C. Biological and Chemical Factors of Importance in the Bioaccumulation and Trophic Transfer of Persistent Organochlorine Contaminants in Arctic Marine Food Webs. Environ. Toxicol. Chem. 2004, 23 (10), 2367-2385.

(20) Lopes, C.; Perga, M.-E.; Peretti, A.; Roger, M.-C.; Persat, H.; Babut, M. Is PCBs Concentration Variability between and within Freshwater Fish Species Explained by Their Contamination Pathways? Chemosphere 2011, 85 (3), 502-508.

(21) Kahilainen, K. K.; Thomas, S. M.; Nystedt, E. K.; Keva, O.; Malinen, T.; Hayden, B. Ecomorphological Divergence Drives Differential Mercury Bioaccumulation in Polymorphic European Whitefish (Coregonus Lavaretus) Populations of Subarctic Lakes. Sci. Total Environ. 2017, 599, 1768-1778.

(22) Borgå, K.; Gabrielsen, G.; Skaare, J. Biomagnification of Organochlorines along a Barents Sea Food Chain. Environ. Pollut. 2001, 113 (2), 187-198.

(23) Catalan, J.; Ventura, M.; Vives, I.; Grimalt, J. O. The Roles of Food and Water in the Bioaccumulation of Organochlorine Compounds in High Mountain Lake Fish. Environ. Sci. Technol. 2004, 38 (16), 4269-4275.

(24) Perga, M.-E.; Nellier, Y.-M.; Cottin, N.; Fanget, P.; Naffrechoux, E. Bioconcentration May Be Favoured over Biomagnification for Fish PCB Contamination in High Altitude Lakes. Inland Waters 2017, 7 (1), 14-26.

(25) Oliver, B. G.; Niimi, A. J. Trophodynamic Analysis of Polychlorinated Biphenyl Congeners and Other Chlorinated Hydrocarbons in the Lake Ontario Ecosystem. Environ. Sci. Technol. 1988, 22 (4), 388-397.

(26) Madenjian, C. P.; Elliott, R. F.; Schmidt, L. J.; Desorcie, T. J.; Hesselberg, R. J.; Quintal, R. T.; Begnoche, L. J.; Bouchard, P. M.; Holey, M. E. Net Trophic Transfer Efficiency of PCBs to Lake Michigan Coho Salmon from Their Prey. Environ. Sci. Technol. 1998, 32 (20), 3063-3067.

(27) Agency for Toxic Substances and Disease Registry. Public Health Statement for Polychlorinated Biphenyls (PCBS). November 2000.

(28) Batias, A. Le Lavaret Du Lac Du Bourget. Productivité et Alevinage. Bull. Fr. Piscic. 1954, No. 173, 150-163.

(29) Visini, V. Salmonidés du lac du Bourget ETUDE DE LEUR REPRODUCTION. August 20, 2008.

(30) Dingemanse, N. J.; Kazem, A. J.; Réale, D.; Wright, J. Behavioural Reaction Norms: Animal Personality Meets Individual Plasticity. Trends Ecol. Evol. 2010, 25 (2), 81-89.

(31) Wolf, M.; Weissing, F. J. Animal Personalities: Consequences for Ecology and Evolution. Trends Ecol. Evol. 2012, 27 (8), 452-461.

(32) Jacquet, S., et Al. Suivi Environnemental Des Eaux Du Lac Du Bourget Pour l'année 2015. 2016.

(33) SOERE OLA-IS, AnaEE-France, INRA of Thonon-Les-Bains, CISALB, 09/04/2019, Developed by the Eco-Informatique ORE System of the INRA.

(34) Nellier, Y.-M.; Perga, M.-E.; Cottin, N.; Fanget, P.; Malet, E.; Naffrechoux, E. Mass Budget in Two High Altitude Lakes Reveals Their Role as Atmospheric PCB Sinks. Sci. Total Environ. 2015, 511, 203-213.

(35) Dargnat, C.; Fisson, C. Les PolyChloroBiphényles (PCB) Dans Le Bassin de La Seine et Son Estuaire. Etude Réalis. Par GIP Seine-Aval 2010.

(36) Minagawa, M.; Wada, E. Stepwise Enrichment of $15 \mathrm{~N}$ along Food Chains: Further Evidence and the Relation between $\triangle 15 \mathrm{~N}$ and Animal Age. Geochim. Cosmochim. Acta 1984, 48 (5), 1135-1140. 
(37) Vander Zanden, M. J.; Cabana, G.; Rasmussen, J. B. Comparing Trophic Position of Freshwater Fish Calculated Using Stable Nitrogen Isotope Ratios $(\Delta 15 N)$ and Literature Dietary Data. Can. J. Fish. Aquat. Sci. 1997, 54 (5), 1142-1158.

(38) Parnell, A. Simmr: A Stable Isotope Mixing Model. R Package Version 0.3.1. 2016.

(39) Post, D. M.; Layman, C. A.; Arrington, D. A.; Takimoto, G.; Quattrochi, J.; Montana, C. G. Getting to the Fat of the Matter: Models, Methods and Assumptions for Dealing with Lipids in Stable Isotope Analyses. Oecologia 2007, 152 (1), 179-189.

(40) Post, D. M. Using Stable Isotopes to Estimate Trophic Position: Models, Methods, and Assumptions. Ecology 2002, 83 (3), 703-718.

(41) Quezada-Romegialli, C.; Jackson, A. L.; Hayden, B.; Kahilainen, K. K.; Lopes, C.; Harrod, C. TRophicPosition, an $r$ Package for the Bayesian Estimation of Trophic Position from Consumer Stable Isotope Ratios. Methods Ecol. Evol 2018, 9, 1292-1299.

(42) Opinion of the Scientific Panel on Contaminants in the Food Chain Related to the Presence of Non Dioxin-like Polychlorinated Biphenyls (PCB) in Feed and Food. EFSA J. 2005, 3 (11).

(43) Agence de l'eau RMC. Base de Données Micropolluants Du Programme PCB. Agence de l'eau RMC, FRANCE 2008.

(44) Olsson, A.; Valters, K.; Burreau, S. Concentrations of Organochlorine Substances in Relation to Fish Size and Trophic Position: A Study on Perch (Perca Fluviatilis L.). Environ. Sci. Technol. 2000, 34 (23), 4878-4886.

(45) Stow, C. A. Factors Associated with PCB Concentrations in Lake Michigan Fish. Environ. Sci. Technol. 1995, 29 (2), 522-527.

(46) Kiriluk, R. M.; Servos, M. R.; Whittle, D. M.; Cabana, G.; Rasmussen, J. B. Using Ratios of Stable Nitrogen and Carbon Isotopes to Characterize the Biomagnification of DDE, Mirex, and PCB in a Lake Ontario Pelagic Food Web. Can. J. Fish. Aquat. Sci. 1995, 52 (12), 2660-2674.

(47) Borgå, K.; Kidd, K. A.; Muir, D. C.; Berglund, O.; Conder, J. M.; Gobas, F. A.; Kucklick, J.; Malm, O.; Powell, D. E. Trophic Magnification Factors: Considerations of Ecology, Ecosystems, and Study Design. Integr. Environ. Assess. Manag. 2012, 8 (1), 64-84.

(48) Brandl, S. J.; Robbins, W. D.; Bellwood, D. R. Exploring the Nature of Ecological Specialization in a Coral Reef Fish Community: Morphology, Diet and Foraging Microhabitat Use. Proc R Soc B 2015, 282 (1815), 20151147.

(49) Guiguer, K.; Reist, J.; Power, M.; Babaluk, J. Using Stable Isotopes to Confirm the Trophic Ecology of Arctic Charr Morphotypes from Lake Hazen, Nunavut, Canada. J. Fish Biol. 2002, 60 (2), 348362.

(50) Ulrich, K. L. Trophic Ecology of Arctic Char (Salvelinus Alpinus L.) in the Cumberland Sound Region of the Canadian Arctic; University of Manitoba (Canada), 2013.

(51) Snorrason, S. S.; Skúlason, S.; Jonsson, B.; Malmquist, H. J.; Jónasson, P. M.; Sandlund, O. T.; Lindem, T. Trophic Specialization in Arctic Charr Salvelinus Alpinus (Pisces; Salmonidae): Morphological Divergence and Ontogenetic Niche Shifts. Biol. J. Linn. Soc. 1994, 52 (1), 1-18.

(52) Lu, G.; Bernatchez, L. Correlated Trophic Specialization and Genetic Divergence in Sympatric Lake Whitefish Ecotypes (Coregonus Clupeaformis): Support for the Ecological Speciation Hypothesis. Evolution 1999, 53 (5), 1491-1505.

(53) Pothoven, S. A.; Nalepa, T. F. Feeding Ecology of Lake Whitefish in Lake Huron. J. Gt. Lakes Res. 2006, 32 (3), 489-501.

(54) Siwertsson, A.; Knudsen, R.; Adams, C. E.; Præbel, K.; Amundsen, P. Parallel and Non-parallel Morphological Divergence among Foraging Specialists in European Whitefish (Coregonus Lavaretus). Ecol. Evol. 2013, 3 (6), 1590-1602. 
582

583

584

585

586

587

588

589

590

591

592
(55) Jenjan, H. B.; Garduño-Paz, M.; Huntingford, F. A.; Adams, C. E. Gill Development in Sympatric Morphs of Arctic Charr from Loch Awe, Scotland: A Hidden Physiological Cost of Macrobenthos Feeding? Ecol. Freshw. Fish 2017.

(56) Amundsen, P.-A.; Bøhn, T.; Våga, G. H. Gill Raker Morphology and Feeding Ecology of Two Sympatric Morphs of European Whitefish (Coregonus Lavaretus); JSTOR, 2004; pp 291-300.

(57) Mackay, D.; Celsie, A. K.; Powell, D. E.; Parnis, J. M. Bioconcentration, Bioaccumulation, Biomagnification and Trophic Magnification: A Modelling Perspective. Environ. Sci. Process. Impacts 2018.

(58) Amiard, J.-C. Les Problèmes Liés à l'échantillonnage et à La Détection Des Éléments Traces En Écotoxicologie.; 1994. 
a)

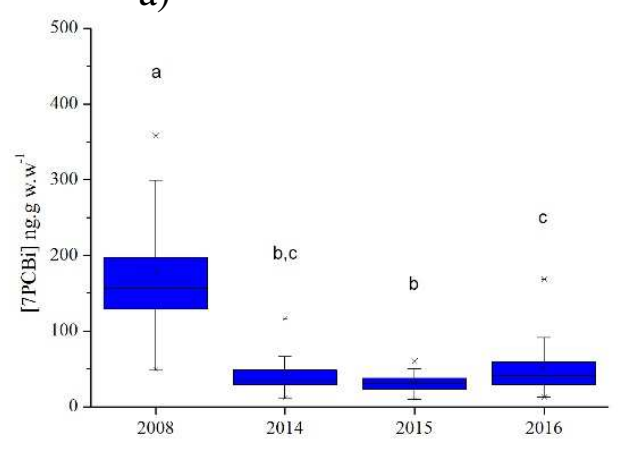

c)

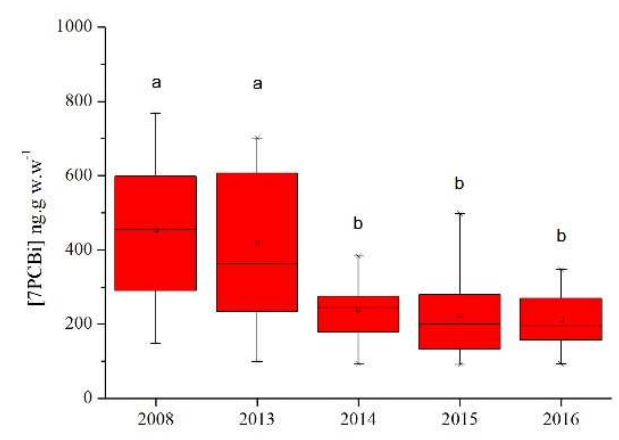

b)

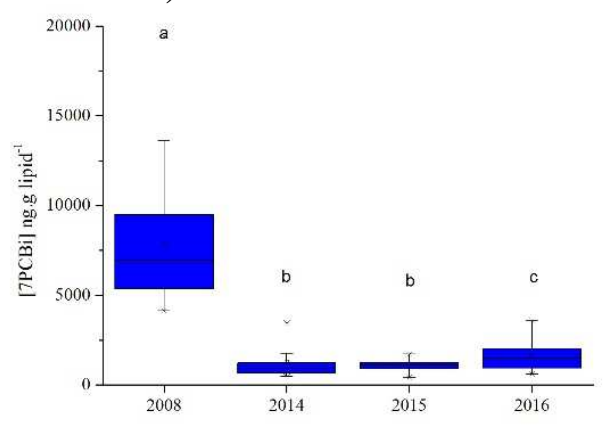

d)

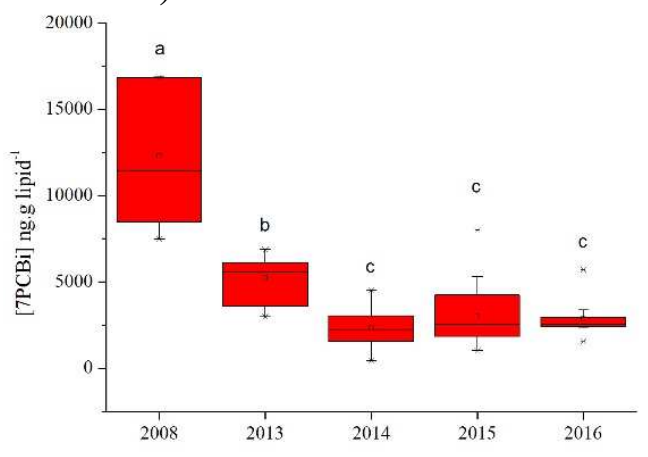

Figure 1: Boxplots of whitefish a) and b), and Arctic char c) and d) wet weight and lipid-normalized PCBi contamination. Letters are used to show statistically significant differences.
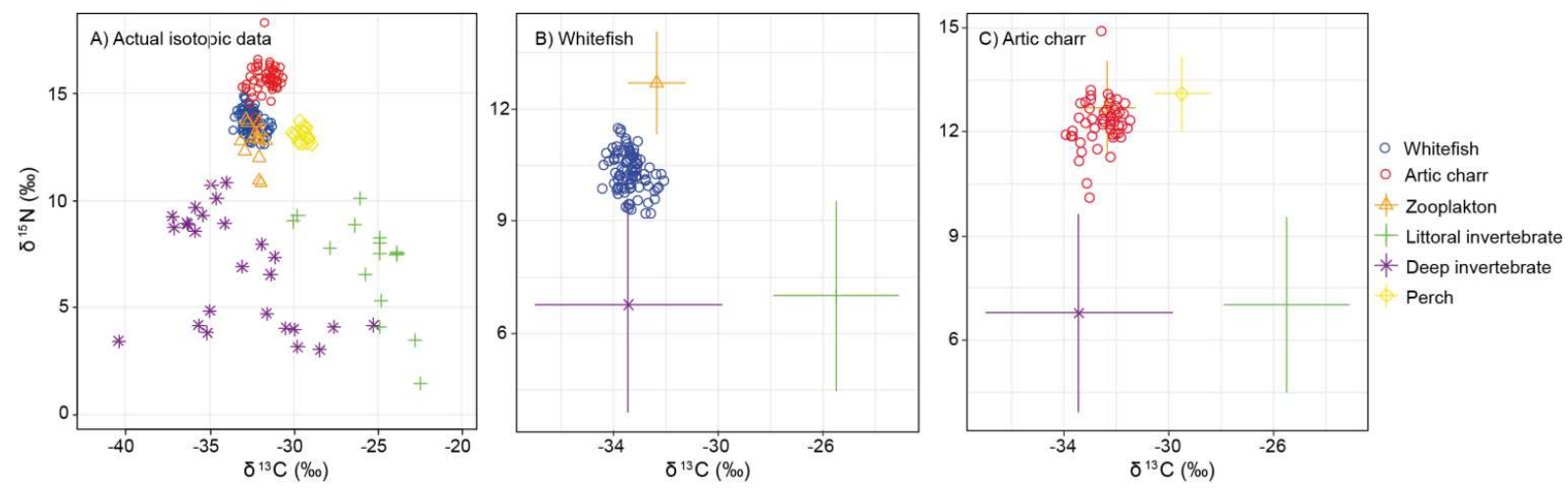

Figure 2: Isotopic space $\delta^{13} \mathrm{C}-\delta^{15} \mathrm{~N}$ showing the different isotopic measurements. A) Actual isotopic data, and isotopic values for B) whitefish and C) Arctic char corrected for isotopic fractionation, highlighting their embedding within isotopic values of putative preys (i.e., $96 \%$ and $89 \%$ of isotopic embedding for Arctic char and whitefish, respectively, when considering the standard deviation of $\pm 1 \%$ o for trophic fractionation). Vertical and horizontal lines in B) and C) indicate standard deviations of the isotopic values for the different resources considered in Bayesian mixing models. 

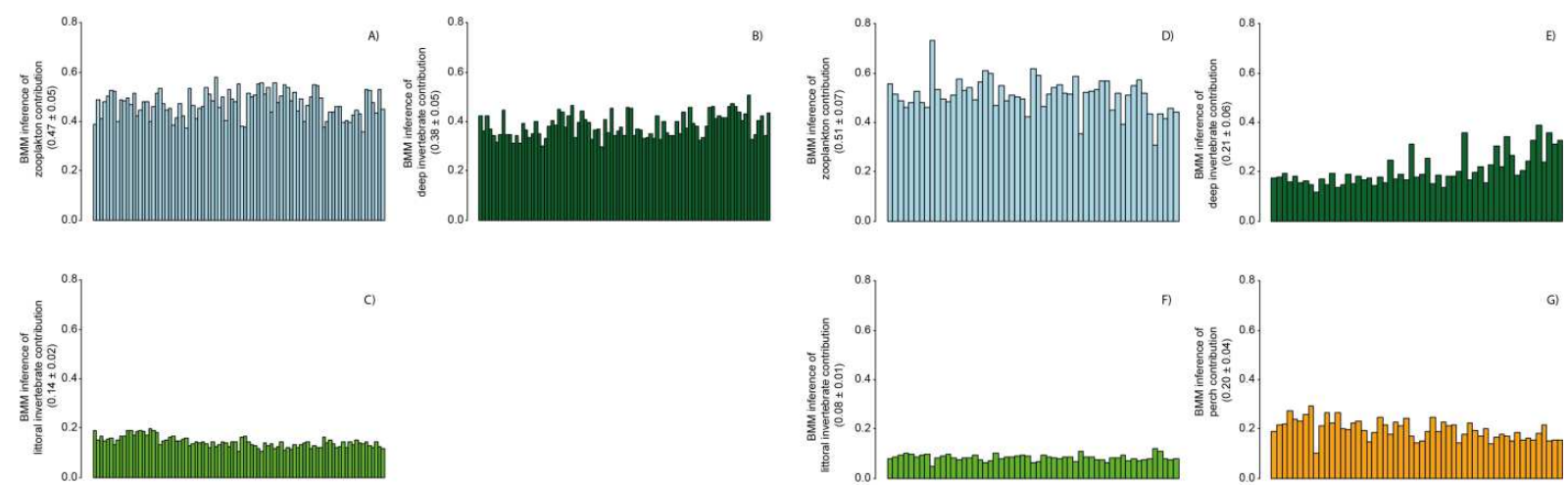

Figure 3: Barplots representing the proportions of the different resources consumed by each individual for the two fish species inferred from the BMMs. For whitefish, barplots represent A) contribution of zooplankton, B) contribution of deep invertebrates and C) contribution of littoral invertebrates. For Arctic char, barplots represent D) contribution of zooplankton, E) contribution of deep invertebrates, F) contribution of littoral invertebrates and G) contribution of yoy perch. Numbers in brackets indicate the mean \pm sd for the different resources.
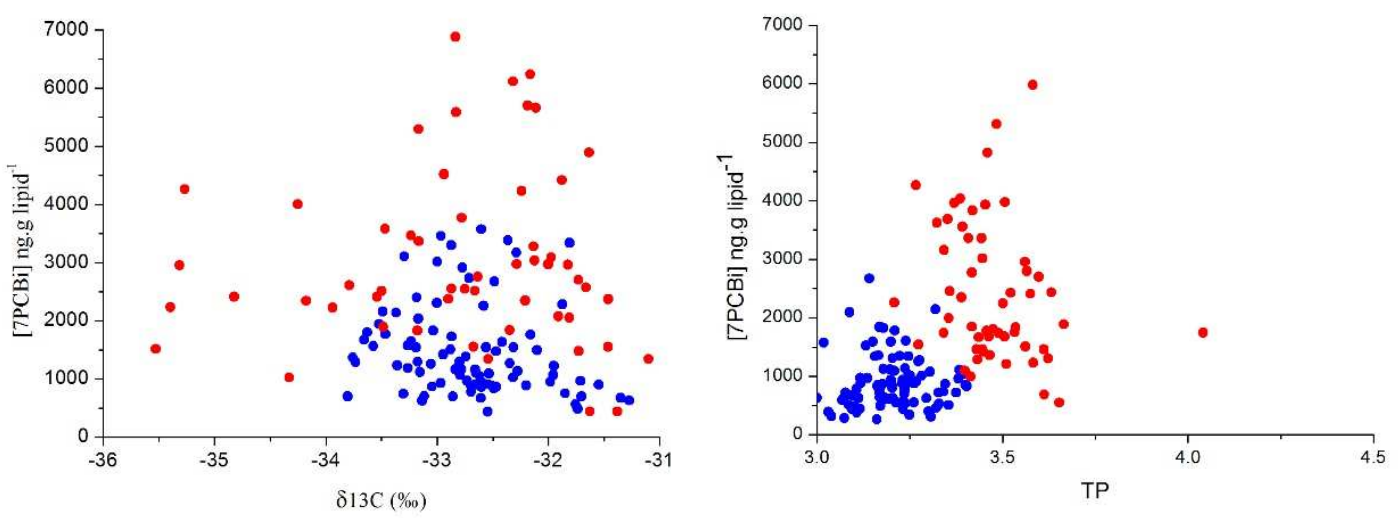

Figure 4: Plots of $\delta^{13} \mathrm{C}(\mathrm{a})$ and TP (b) vs $\Sigma 7 \mathrm{PCBi}$ concentration for Arctic char $(\bullet)$ and whitefish (•).

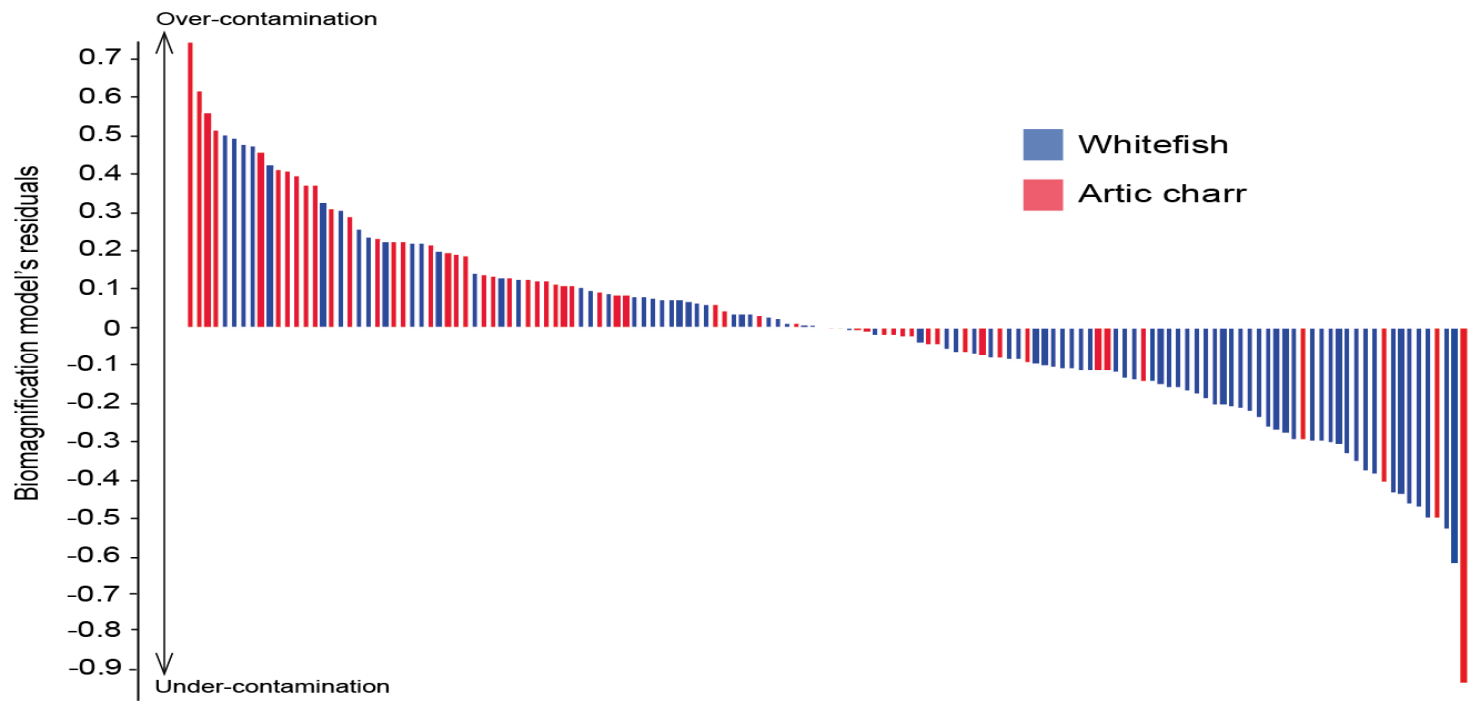


Figure 5: Individual residuals of the biomagnification model ranging from positive to negative residuals, representing a gradient of over- to undercontamination.
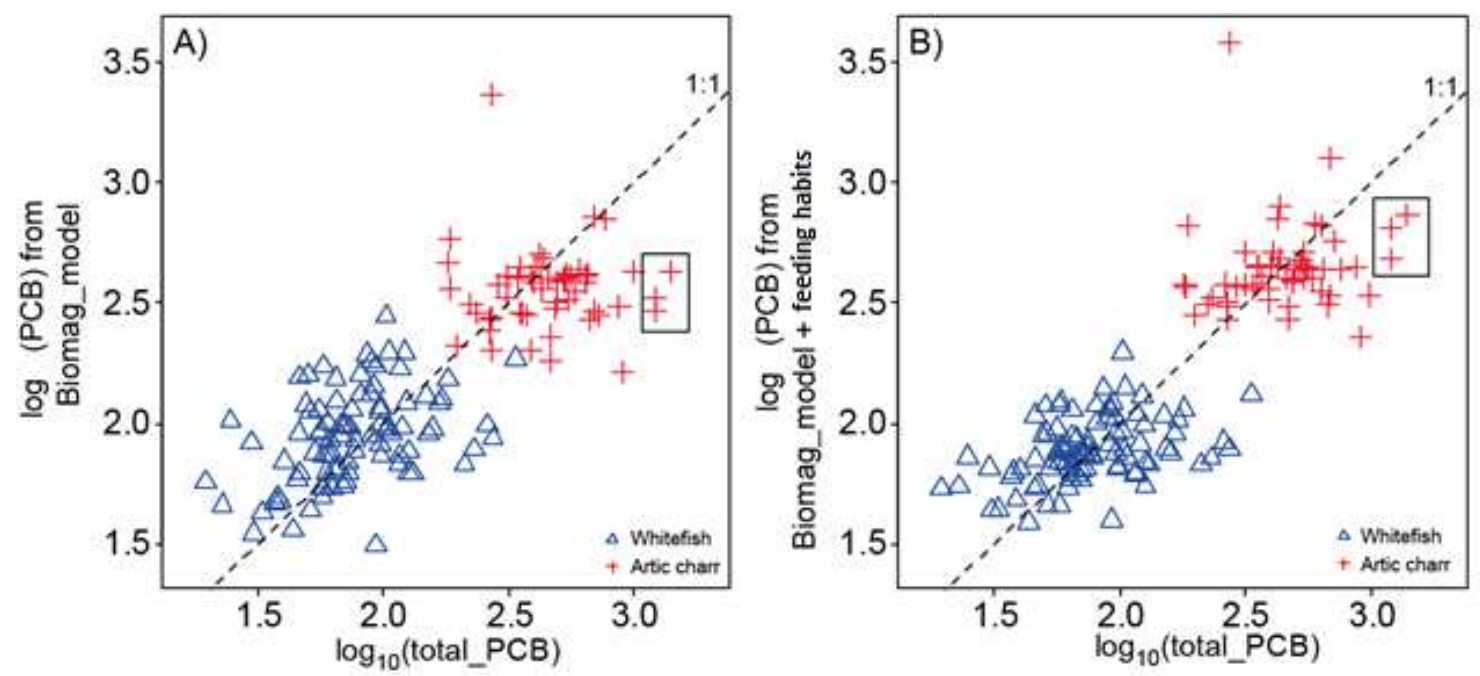

Figure 6: Biplot of $A$ ) the relationships between the predicted $\mathrm{PCB}$ concentrations by the biomagnification model (i.e., equation 4) and the measured total $\mathrm{PCB}$ concentrations and $\mathrm{B}$ ) the relationships between the predicted PCB concentrations inferred by the biomagnification model corrected by the individual feeding habits (i.e., equation 8) and the measured total PCB concentrations. Boxes indicated the most important corrections applied to three Arctic char individuals. 


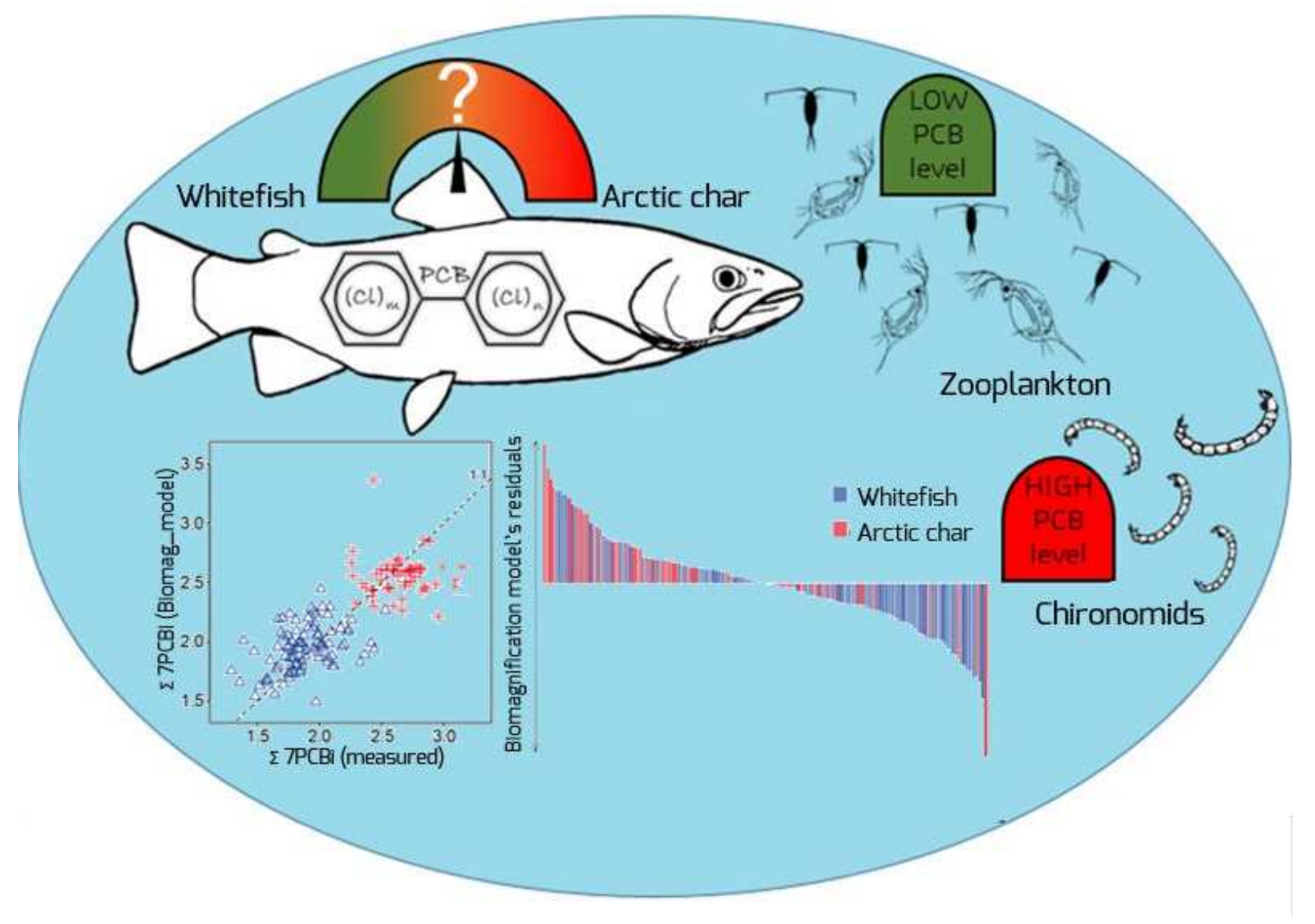

